\title{
Promoting Physical Activity During the COVID-19 Pandemic: Implications for Obesity and Chronic Disease Management
}

\author{
Geoffrey M. Hudson and Kyle Sprow
}

Physical activity is important for prevention and management of numerous chronic diseases, including cardiovascular disease and type 2 diabetes. ${ }^{1-3}$ People with higher levels of physical activity have lower all-cause mortality, improved immune function, and better recovery from upper respiratory and microbial infections. ${ }^{4-8}$ In contrast, people who are sedentary and obese have increased mortality and hospitalizations from such infections. ${ }^{5,9-12}$ Obesity was recently linked to an increased risk of severe (and often fatal) complications from influenza A virus H1N1 infection during the 2009 pandemic. ${ }^{5}$ While there is still a lot to learn regarding the novel coronavirus disease 2019 (COVID-19), lessons can be learned from the impact that both physical activity and obesity have had on disease progression during recent influenza outbreaks. 9

\section{Increased Severity of COVID-19 Symptoms in Obese and Sedentary Populations}

COVID-19 is a respiratory disease caused by severe acute respiratory syndrome-coronavirus 2 (SARS-CoV-2). The highly contagious and transmissible characteristics, including asymptomatic transmission, of SARS-CoV-2, as well as the absence of a proven treatment, have accelerated the spread of the disease and have overwhelmed hospitals worldwide. ${ }^{13}$ While SARS-CoV-2 affects all demographic sectors, COVID-19 disproportionally affects older adults and those with pre-existing conditions. ${ }^{14,15}$ A study of more than 5,200 hospitalized patients with COVID-19 reported a strong association between obesity and critical illness. ${ }^{12}$ Patients under age 60 years who were overweight were twice as likely to be hospitalized as their leaner counterparts, while those with obesity were three times as likely to need intensive care. These findings contribute to the growing body of evidence that obesity and other chronic conditions likely predispose an individual to increased risks associated with contraction of infectious diseases. ${ }^{10-12}$

Given that nearly $40 \%$ of Americans ${ }^{16}$ could be classified as obese and more than $75 \%$ do not meet the physical activity guidelines, ${ }^{1}$ a meaningful proportion of the United States may be at an elevated risk for critical complications if they contract COVID-19. Excess adiposity compromises immune function and impedes the body's acute and adaptive responses to infections. ${ }^{6,9}$ Particularly, patients with obesity-related metabolic disorders have chronic levels of inflammation and circulating cytokines that result in dysregulated immune responses and impaired maturation of $\mathrm{B}$ and T cells. ${ }^{5,9}$

Hudson is with the Department of Health, Kinesiology, and Sport, University of South Alabama, Mobile, AL, USA. Sprow is with the Office of the Assistant Secretary for Preparedness and Response, Aveshka, Washington, DC, USA. Hudson (ghudson@southalabama.edu) is corresponding author.

\section{Importance of Physical Activity to Attenuate the Impact of COVID-19}

Federal, state, and local governments have issued a series of prevention and mitigation policies to help reduce the burden of COVID-19. ${ }^{17}$ These policies include social distancing, stayat-home orders, telework recommendations, and closures of schools and non-essential business. ${ }^{18}$ While these policies are essential in reducing transmission of the virus and the overall burden of the pandemic, they have fostered an environment of physical inactivity and deconditioning. ${ }^{19-21}$ Similar to obesity, physical inactivity increases the severity of symptoms and risk of mortality in those with chronic diseases or acute respiratory infections. $3,4,6,8,9,22$ The inhibited immune response and blunting of macrophage activation appears to be associated with the diminished insulin sensitivity that occurs with reduced physical activity. ${ }^{7,23}$ Exercise increases a person's physiologic reserve, thereby lowering the risk of mortality from cardiovascular and metabolic diseases, as well as many types of cancer. ${ }^{3,4,20-22,24}$ Exercise also provides immunological benefits that are mediated by enhanced immuno-surveillance via augmented macrophage responses, increased circulation of immunoglobulins and anti-inflammatory cytokines, and an attenuation of inflammation. ${ }^{6-9}$ Therefore, it is important to encourage physical activity that abides by state and local mitigation policies to assist with disease management and increase physiologic reserve beyond the immediate SARS-CoV-2 pandemic. ${ }^{20,25}$

\section{Practical Exercise Guidance During the COVID-19 Pandemic}

The public health strategies put forth to limit person-to-person transmission of the virus have made it difficult for many to maintain structured exercise programs that necessitate recreational facilities, team sport complexes, and fitness centers. ${ }^{8}$ On the other hand, while the social-distancing measures may limit the opportunity for many to participate in structured exercise programs, they have also increased potential opportunities for leisure-time physical activity such as family walks, hiking, canoeing, gardening, yard maintenance, and other outdoor activities. Traditional aerobic endurance activities such as jogging, running, biking, and rowing are still very effective means of meeting physical activity guidelines given that one either can safely take part in these activities outdoors (while maintaining appropriate social distancing) or has ergometer equipment in their home. Pilates, yoga, and dancing are also excellent activities for those unable to exercise outside of the home. These latter activities require minimal equipment and there is an abundance of classes that are available through videos or online. Moreover, these workouts are a great alternative to traditional 
aerobic activities, as they are scalable and can be adapted for beginners to more advanced athletes. Body weight, isometric, resistance band, and hand-held weight exercises can also be an acceptable alternative to traditional resistance training regimens. The American College of Sports Medicine provides some valuable resources on how to stay physically active during a pandemic. ${ }^{26}$ Additionally, the COVID-19 Taskforce of the National Strength and Conditioning Association has provided helpful strategies and guidelines for athletes and team sports administrators to carefully plan safe returns to training. ${ }^{27}$

Social support, a key component for many individuals to start or maintain a physical activity program, is particularly challenging in the current pandemic environment. A benefit of personal training, group fitness classes, and team sports is the accountability and social support that they provide. This support helps to improve adherence to exercise programs and meet physical activity and health-related goals. Social media, virtual support groups, and fitness apps with community support can help to provide the encouragement and motivation necessary to facilitate these behavior changes. ${ }^{28}$

Additional precautions should be implemented as stay-athome orders/recommendations are relaxed. ${ }^{21}$ It is important for everyone to continue to practice proper social distancing and to employ aggressive personal hygiene and sanitation protocols in public gyms and fitness centers. The Centers for Disease Control and Prevention (CDC) has provided guidance about ways to protect yourself and others when returning to recreational facilities. ${ }^{29}$ The CDC has also provided considerations for youth sports $^{30}$ and summer camps. ${ }^{31}$ While many of these suggestions vary, they both share a continuum of theoretical risk. The lowest level of risk for youth sports involves physical conditioning and skill-building drills in the home environment with family members, whereas close-contact, team competitions against people from different geographic locations presents the highest level of risk.

Physical activity is essential for maintaining proper health and physical function even during a pandemic. Maintaining proper physical conditioning can improve immune function and potentially protect a person from serious complications related to respiratory infections. Given the high transmissibility of the SARS$\mathrm{CoV}-2$, however, one must remain vigilant about seeking safe physical activity environments and following guidance from health officials to limit the spread of the virus.

\section{References}

1. U.S. Department of Health and Human Services. Physical Activity Guidelines for Americans 2nd Edition. Washington, DC: U.S. Department of Health and Human Services; 2018.

2. Colberg SR, Sigal RJ, Yardley JE, et al. Physical activity/exercise and diabetes: A position statement of the American Diabetes Association. Diabetes Care. 2016;39(11):2065-2079. PubMed ID: 27926890 doi: $10.2337 / \mathrm{dc} 16-1728$

3. Lavie CJ, Ozemek C, Carbone S, Katzmarzyk PT, Blair SN. Sedentary behavior, exercise, and cardiovascular health. Circ Res. 2019; 124(5):799-815. PubMed ID: 30817262 doi:10.1161/CIRCRES AHA.118.312669

4. Carlson SA, Adams EK, Yang Z, Fulton JE. Percentage of deaths associated with inadequate physical activity in the United States. Prev Chronic Dis. 2018;15:E38. PubMed ID: 29602315 doi:doi:10.5888/ pcd18.170354
5. Sun Y, Wang Q, Yang G, Lin C, Zhang Y, Yang P. Weight and prognosis for influenza $\mathrm{A}(\mathrm{H} 1 \mathrm{~N} 1) \mathrm{pdm} 09$ infection during the pandemic period between 2009 and 2011: A systematic review of observational studies with meta-analysis. Infect Dis (Auckl). 2016; 48(11-12):813-822. doi:10.1080/23744235.2016.1201721

6. Nieman DC, Wentz LM. The compelling link between physical activity and the body's defense system. J Sport Health Sci. 2019; 8(3):201-217. PubMed ID: 31193280 doi:10.1016/j.jshs.2018. 09.009

7. Zheng Q, Cui G, Chen J, et al. Regular exercise enhances the immune response against microbial antigens through up-regulation of toll-like receptor signaling pathways. Cell Physiol Biochem. 2015;37(2):735746. PubMed ID: 26356264 doi:10.1159/000430391

8. Laddu DR, Lavie CJ, Phillips SA, Arena R. Physical activity for immunity protection: Inoculating populations with healthy living medicine in preparation for the next pandemic [published online ahead of print April 9, 2020]. Prog Cardiovasc Dis. doi:10.1016/j. pcad.2020.04.006

9. Luzi L, Radaelli MG. Influenza and obesity: Its odd relationship and the lessons for COVID-19 pandemic. Acta Diabetol. 2020;57(6): 759-764. PubMed ID: 32249357 doi:10.1007/s00592-020-01522-8

10. Andersen CJ, Murphy KE, Fernandez ML. Impact of obesity and metabolic syndrome on immunity. Adv Nutr. 2016;7(1):66-75. PubMed ID: 26773015 doi:10.3945/an.115.010207

11. Zhou F, Yu T, Du R, et al. Clinical course and risk factors for mortality of adult inpatients with COVID-19 in Wuhan, China: a retrospective cohort study. Lancet. 2020;395(10229):1054-1062. PubMed ID: 32171076 doi:10.1016/S0140-6736(20)30566-3

12. Petrilli CM, Jones SA, Yang J, et al. Factors associated with hospitalization and critical illness among 4,103 patients with Covid-19 disease in New York City: Prospective cohort study. $\mathrm{Br}$ Med J. 2020;369:m1966. doi:10.1101/2020.04.08.20057794

13. Khafaie MA, Rahim F. Cross-country comparison of case fatality rates of Covid-19/SARS-CoV-2. Osong Public Health Res Perspect. 2020;11(2):74-80. PubMed ID: 32257772 doi:10.24171/j.phrp.2020. 11.2.03

14. CDC. People who may be at increased risk for MERS. Middle East Respiratory Syndrome (MERS). https://www.cdc.gov/coronavirus/ mers/risk.html.

15. Wu J, Xu F, Zhou W, et al. Risk factors for SARS among persons without known contact with SARS patients, Beijing, China. Emerg Infect Dis. 2004;10(2):210-216. PubMed ID: 15030685 doi:10.3201/ eid1002.030730

16. Hales CM, Carroll MD, Fryar CD, Ogden CL. Prevalence of Obesity Among Adults and Youth: United States, 2015-2016 Key Findings Data from the National Health and Nutrition Examination Survey. 2015. https://www.cdc.gov/nchs/data/databriefs/ db288_table.pdf\#1.

17. Department of Homeland Security. Master question list for COVID19 (caused by SARS-CoV-2): Weekly Report. May 19 2020. https:// www.dhs.gov/publication/st-master-question-list-covid-19. Accessed May 21, 2020.

18. CDC. How coronavirus spreads. https://www.cdc.gov/coronavirus/ 2019-ncov/prevent-getting-sick/how-covid-spreads.html?CDC_AA_ref Val=https $\% 3 \mathrm{~A} \% 2 \mathrm{~F} \% 2 \mathrm{Fwww}$. cdc.gov\%2Fcoronavirus\%2F2019-ncov \%2Fprepare\%2Ftransmission.html. Accessed April 26, 2020.

19. Carter SJ, Baranauskas MN, Fly AD. Considerations for obesity, vitamin $\mathrm{D}$, and physical activity amidst the COVID-19 pandemic [published online ahead of print April 16, 2020]. Obesity. 2020; 1-2. doi:10.1002/oby.22838

20. Jiménez-Pavón D, Carbonell-Baeza A, Lavie CJ. Physical exercise as therapy to fight against the mental and physical consequences of 
COVID-19 quarantine: Special focus in older people [published online ahead of print March 24, 2020]. Prog Cardiovasc Dis. doi:10. 1016/j.pcad.2020.03.009

21. Chen P, Mao L, Nassis GP, Harmer P, Ainsworth BE, Li F. Coronavirus disease (COVID-19): The need to maintain regular physical activity while taking precautions. J Sport Health Sci. 2020;9(2):103104. PubMed ID: 32099716 doi:10.1016/j.jshs.2020.02.001

22. Stamatakis E, Gale J, Bauman A, Ekelund U, Hamer M, Ding D. Sitting time, physical activity, and risk of mortality in adults. $J$ Am Coll Cardiol. 2019;73(16):2062-2072. PubMed ID: 31023430 doi:10.1016/j.jacc.2019.02.031

23. Reidy PT, Yonemura NM, Madsen JH, et al. An accumulation of muscle macrophages is accompanied by altered insulin sensitivity after reduced activity and recovery. Acta Physiol. 2019;226(2). doi:10.1111/apha.13251

24. Mctiernan A, Friedenreich CM, Katzmarzyk PT, et al. Physical activity in cancer prevention and survival: A systematic review. Med Sci Sports Exerc. 2019;51(6):1252-1261. PubMed ID: 31095082 doi:10.1249/ MSS.0000000000001937

25. Kissler SM, Tedijanto C, Goldstein E, Grad YH, Lipsitch M. Projecting the transmission dynamics of SARS-CoV-2 through the postpandemic period. Science. 2020;368(6493):860-868. PubMed ID: 32291278 doi:10.1126/science.abb5793
26. American College of Sports Medicine. Staying physically active during the COVID-19 pandemic. March 16 2020. https://www.acsm. org/read-research/newsroom/news-releases/news-detail/2020/03/16/ staying-physically-active-during-covid-19-pandemic. Accessed May 27, 2020.

27. National Strength and Conditioning Association. NSCA COVID-19 Taskforce return to training resources. 2020; https://www.nsca.com/ education/tools-and-resources/covid-19-return-to-training/. Accessed May 27, 2020.

28. Sittig S, Hauff C, Graves RJ, et al. Characteristics of and factors influencing college nursing students' willingness to utilize mHealth for health promotion. Comput Inform Nurs. 2020;38(5):246-255. PubMed ID: 32032084 doi:10.1097/CIN.0000000000000600

29. CDC. Visiting parks and recreational facilities: Protect yourself and others from COVID-19. 2020; https://www.cdc.gov/coronavirus/ 2019-ncov/daily-life-coping/visitors.html. Accessed May 20, 2020.

30. CDC. Coronavirus Disease 2019 (COVID-19): Considerations for youth sports. 2020; https://www.cdc.gov/coronavirus/2019-ncov/ community/schools-childcare/youth-sports.html. Accessed May 21, 2020.

31. CDC. Coronavirus Disease 2019 (COVID-19): Considerations for youth and summer camps. 2020; https://www.cdc.gov/coronavirus/ 2019-ncov/community/schools-childcare/summer-camps.html. Accessed May 21, 2020. 